\title{
Application of polymer thermal store material in fixed honeycomb regenerative heat exchanger
}

\author{
Angel Penev ${ }^{1, *}$, and Lyubomir Tsokov ${ }^{1}$ \\ ${ }^{1}$ Technical University of Sofia, Thermal and Refrigeration Engineering Department, Sofia, Bulgaria
}

\begin{abstract}
The article considers the possibility to use different types of polymer thermal store materials for regenerative heat exchangers in local ventilation systems. The research provides evidence for the benefits of the replacement of the most commonly used metal and non-metallic materials in the manufacture of the regenerator honeycomb matrix. It does so by presenting the results of calculations and comparative analysis of the influence of thermo-physical properties of a wide range of polymers on the thermal efficiency of a fixed counter-flow regenerator operating with humid air. In order to evaluate the efficiency, we have used a numerical solution of the system of mathematical physics equations describing the process in the regenerator. The system also includes an appropriate CFD model of the evaporation-condensation phase change process.
\end{abstract}

Key words: regenerator, honeycomb matrix, polymers, humid air, CFD;

\section{Introduction}

Regenerators are widely used in ventilation systems for heat recovery of the exhaust humid air. Their usage is closely related to the economy of energy of the microclimate of buildings and the provision of quality and comfort for the indoor air. Compared to industrial regenerators, which operate under almost constant conditions, regenerators in ventilation systems operate with variable climate conditions - variable temperature, humidity, pressure difference, variable flow rate of hot and cold air, etc. This leads to unfavorable operating regimes of the regenerator, also including condensation of the water vapor from the airflow into the channel's wall. The condensate on to the walls could be absorbed by the material and this would lead to changing the thermal-physical properties of the matrix, to an accumulation of contaminants and creating colonies of bacteria.

Heat and mass transfer process in the airflow can be researched by modeling and simulating the regenerator's efficiency in different conditions, close to the actual operating regime. For this purpose, we use a three-dimensional multi-physical mathematical model that contains the equations of heat and mass transfer, aerodynamics, and condensationevaporation of the water vapor of humid air on to the wall surface of the matrix's channel. The model does not include the fog formation phenomenon into the volume of the channel.

Thermal store bodies are usually made from different types of materials, which practically depend on the operating conditions and requirements, temperature, and

\footnotetext{
* Angel Penev: gartz@,tu-sofia.bg
} 
efficiency. For cryogenic applications with extremely low temperatures ranged between 15 and $300 \mathrm{~K}$, the most appropriate materials to be used are thermal store metals such as steel, aluminum, bronze, copper, etc., [1]. For waste heat recovery and application related to the combustion process with high temperatures from 300 to $1600 \mathrm{~K}$, more appropriate materials would be some metals and ceramics materials such as cordierite, dense alumina, mullite, corundum mullite, etc., [2]. Despite the many different applications of the materials, the thermal efficiency of the regenerator requires materials with high volume heat capacity $\rho c_{R}$ and low thermal conductivity $\lambda$, [3]. Unfortunately, research about using polymer materials for manufacturing the thermal store matrix in the regenerative heat exchangers is currently little discussed in the literature, $[4,5]$.

Finally, the main purpose of this article is to evaluate and compare the possibility to use polymer materials in fixed counter-flow regenerative heat exchangers in HVAC.

\section{Numerical mathematical model}

\subsection{Geometry of the model}

The geometry and dimensions of the matrix are in millimeters and are shown in Fig.1. The diameter of the cylinder is $\mathrm{D}=93 \mathrm{~mm}$, and its length is $\mathrm{L}=99 \mathrm{~mm}$. The channels are square the free-cross-section is $2.4 \mathrm{~mm} \times 2.4 \mathrm{~mm}$ and the wall thickness between them is $\delta=1 \mathrm{~mm}$. It is assumed that the material which the matrix is made is homogeneous and isotropic, that the distribution of airflow is uniform throughout all channels. Due to the symmetry of the temperature field, the average surface of the wall between the channels is adiabatic, which allows the computational model to be reduced to only one channel with half the thickness of its walls, ignoring the influence of deformation of geometry and temperature field of the matrix. The front surfaces of the channel walls are also assumed to be adiabatic.

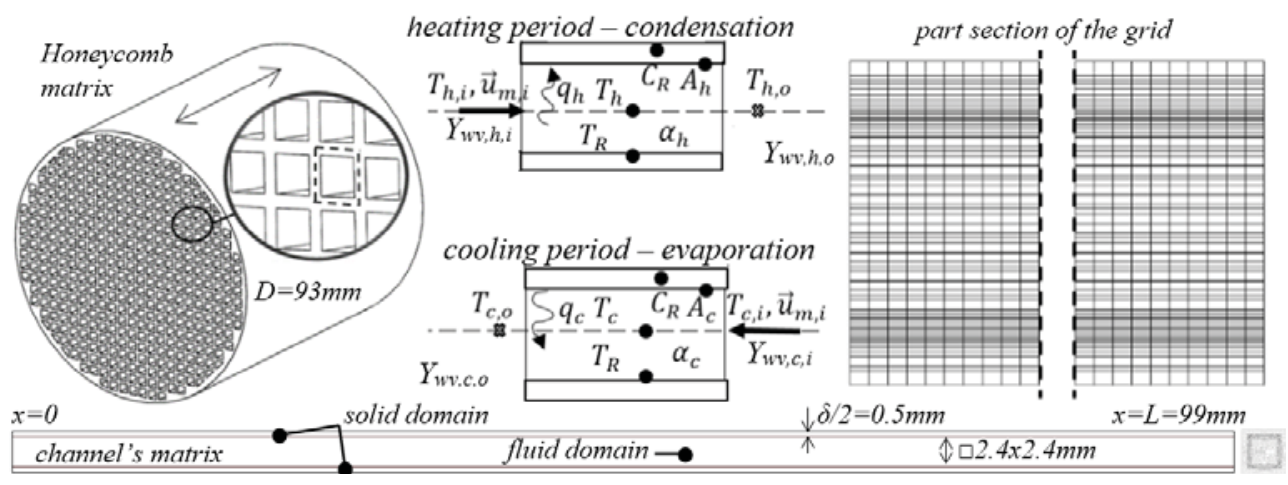

Fig. 1. Honeycomb matrix, the process into the channel at $\mathrm{x}=0$ and $\mathrm{x}=\mathrm{L}$ and the computational grid.

\subsection{Numerical Method}

The numerical method for solving the system of differential equations is computational fluid dynamics based on the Finite Volume Method, [6] and the commercial software is Fluent, ANSYS, [7, 8]. Appropriate program code is written with GUI commands which provide automatic switching of the half-periods to reach quasi-steady-state regime. There are two spatial domains for the fluid and solid, Figure.1, identical with the previous papers, [9-11].The meshing method is "inflation", which means fine layer mesh near to the walls and is recommended for wall film phase change processes, [12]. The time step is 0.01 . 


\subsection{Differential equations of heat, mass transfer processes and aerodynamics}

Table 1. The system of differential equations of the numerical CFD models.

\begin{tabular}{|c|c|}
\hline \multicolumn{2}{|c|}{ The species mixture transport model } \\
\hline $\begin{array}{c}\text { Continuity equation for the mixture } \\
\frac{\partial \rho \times Y_{i}}{\partial \tau}+\frac{\partial(\rho \times \mathrm{u}) \times Y_{i}}{\partial \mathrm{x}}+\frac{\partial(\rho \times \mathrm{v}) \times Y_{\mathrm{i}}}{\partial \mathrm{y}}+\frac{\partial(\rho \times \mathrm{w}) \times \mathrm{Y}_{\mathrm{i}}}{\partial \mathrm{Z}}=0\end{array}$ & $\begin{array}{l}\text { Mass diffusion in laminar flows } \\
\qquad \vec{J}_{\mathrm{i}}=-\rho \times \mathrm{D}_{\mathrm{i}, \mathrm{m}} \times \nabla \mathrm{Y}_{\mathrm{i}}-\mathrm{D}_{\mathrm{T}, \mathrm{i}} \frac{\nabla \mathrm{T}}{\mathrm{T}}\end{array}$ \\
\hline 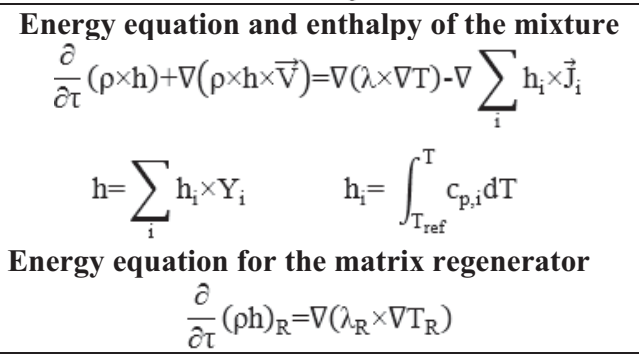 & $\begin{array}{l}\text { Momentum equations, Navier-Stokes } \\
\frac{\partial}{\partial \tau}(\rho \times \mathrm{u})+\nabla(\rho \times \mathrm{u} \times \overrightarrow{\mathrm{V}})=\nabla(\mu \times \nabla \mathrm{u})-\frac{\partial \mathrm{p}}{\partial \mathrm{x}} \\
\frac{\partial}{\partial \tau}(\rho \times \mathrm{v})+\nabla(\rho \times \mathrm{v} \times \overrightarrow{\mathrm{V}})=\nabla(\mu \times \nabla v)-\frac{\partial \mathrm{p}}{\partial y} \\
\frac{\partial}{\partial \tau}(\rho \times w)+\nabla(\rho \times \mathrm{w} \times \overrightarrow{\mathrm{V}})=\nabla(\mu \times \nabla w)-\frac{\partial \mathrm{p}}{\partial z}\end{array}$ \\
\hline The Eulerian Wall Film model for phase cha & coupling with mixture transport model \\
\hline $\begin{array}{c}\text { Continuity equation for the wall film } \\
\qquad \frac{\partial \delta_{\mathrm{f}}}{\partial \tau}+\nabla_{\mathrm{s}} \times\left[\delta_{\mathrm{f}} \times \overrightarrow{\mathrm{V}}_{\mathrm{f}}\right]=\frac{\dot{\mathrm{m}}_{\mathrm{s}}}{\rho_{\mathrm{f}}} \\
\text { Energy equation for the wall film } \\
\frac{\partial\left(\delta_{\mathrm{f}} \mathrm{T}_{\mathrm{f}}\right)}{\partial \tau}+\nabla_{\mathrm{s}}\left(\delta_{\mathrm{f}} \overrightarrow{\mathrm{V}}_{\mathrm{f}} \mathrm{T}_{\mathrm{f}}\right)=\frac{1}{\rho \mathrm{C}_{\mathrm{p}}} 2 \lambda_{\mathrm{f}}\left[\frac{\mathrm{T}_{\mathrm{s}}+\mathrm{T}_{\mathrm{w}}}{\delta_{\mathrm{f}}}-\frac{2 \mathrm{~T}_{\mathrm{f}}}{\delta_{\mathrm{f}}}\right]+\dot{\mathrm{q}}_{\mathrm{im}}+\dot{\mathrm{m}}_{\mathrm{v}} \mathrm{r} \mathrm{T}_{\mathrm{s}}\end{array}$ & 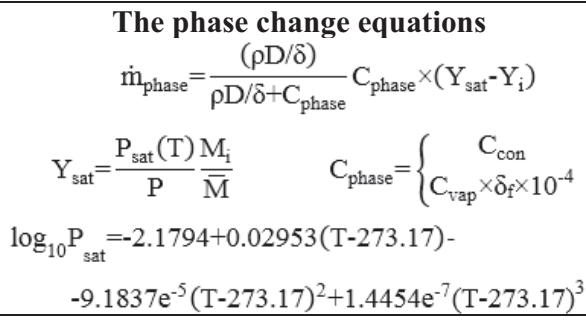 \\
\hline
\end{tabular}

Where $\mathrm{V}, \mathrm{u}, \mathrm{v}, \mathrm{w}$ is the vector of the velocity of the flow and its orthogonal projections, $\mathrm{m} / \mathrm{s}$; $\rho, \lambda, \mathrm{c}_{\mathrm{p}}, \mu$ - density, $\mathrm{kg} / \mathrm{m}^{3}$, thermal conductivity, $\mathrm{W} /(\mathrm{m} . \mathrm{K})$, heat capacity at $\mathrm{p}=$ const, $\mathrm{J} / \mathrm{kgK}$, and dynamic viscosity, N.s $/ \mathrm{m}^{2}$;

$\rho_{R}, \lambda_{R}, c_{R}-$ density, $\mathrm{kg} / \mathrm{m}^{3}$ and thermal conductivity, $\mathrm{W} /(\mathrm{m} . \mathrm{K})$, heat capacity matrix, $\mathrm{J} / \mathrm{kgK}$.

$\mathrm{Y}_{\mathrm{i}}$ - mass fraction for $\mathrm{i}$-th species, $\mathrm{kg}_{\mathrm{i}} / \mathrm{kg}_{\text {mixture; }}$;

$\mathrm{J}_{\mathrm{i}}-$ mass diffusion flux for laminar, $\mathrm{kg} / \mathrm{m}^{2} \mathrm{~s}$;

$\mathrm{D}, \mathrm{D}_{\mathrm{i}, \mathrm{m}}, \mathrm{D}_{\mathrm{T}, \mathrm{i}}$ - mass diffusion coefficient, mass diffusion coefficient for $\mathrm{i}$-th species and thermal mass diffusion coefficient $\mathrm{m}^{2} / \mathrm{s}$;

$\mathrm{P}_{\text {sat }}, \mathrm{P}$ - saturation pressure, absolute pressure, $\mathrm{Pa}$;

$T, T_{R}, T_{s}, T_{f}-$ temperature of the flow, temperature of the regenerator, temperature of the film, average temperature of the film, $\mathrm{K}$;

$\delta, \delta_{\mathrm{f}}-$ distance from the grid cell center to the wall, the film height, $\mathrm{m}$;

$\mathrm{M}_{\mathrm{i}}, \mathrm{M}-$ molecular weight of the vapor species and the mixture, $\mathrm{kg} / \mathrm{kmol}$;

$\dot{\mathrm{m}}_{\mathrm{phasz}} \mathrm{m}_{z} \mathrm{~m}_{\mathrm{v}}$-rate of phase change, $\mathrm{kg} / \mathrm{m}^{2} \mathrm{~s}$, rate of mass source per unit wall area due to droplet collection, $\mathrm{kg} / \mathrm{m}^{2} \mathrm{~s}$, mass rate of the evaporation and the condensation, $\mathrm{kg} / \mathrm{m}^{2} \mathrm{~s}$;

$\mathrm{h}, \mathrm{h}_{\mathrm{R}}$ - specific enthalpy of the species mixture and the regenerator, $\mathrm{J} / \mathrm{kg}$;

$\mathrm{C}_{\text {phase }}, \mathrm{C}_{\mathrm{con}}, \mathrm{C}_{\mathrm{vap}}$ - phase change constant, condensation constant and evaporation constant;

$\dot{\mathrm{q}}_{\mathrm{im}}$ - source term due to liquid impingement from the bulk flow to the surface;

$\mathrm{r}-$ the latent heat associated with the phase change, $\mathrm{J} / \mathrm{kg}$;

$\mathrm{q}$ - the heat flux, $\mathrm{W} / \mathrm{m}^{2}$.

\subsection{Initial and boundary conditions}

The Boundary conditions of the heat transfer between the flow and the regenerator's matrix are as follow:

$$
\mathrm{T}_{\mathrm{w}}=\mathrm{T}_{\mathrm{w}, \mathrm{R}}
$$


where: the index " $\mathrm{W}$ " is the wall surface on the channel and " $\mathrm{R}$ " is the matrix;

The numerical simulation starts from the state of heat-mass equilibrium:

$$
\mathrm{T}_{\mathrm{R}}(\mathrm{x}, \mathrm{y}, \mathrm{z}, 0)=\mathrm{T}(\mathrm{x}, \mathrm{y}, \mathrm{z}, 0)=\mathrm{T}_{\mathrm{o}}, \quad \mathrm{Y}_{\mathrm{wv}}(\mathrm{x}, \mathrm{y}, \mathrm{z}, 0)=\mathrm{Y}_{\mathrm{wv}, \mathrm{o}} \quad 0 \leq \mathrm{x} \leq \mathrm{L}
$$

For each flow switching, the temperature field in the matrix and the fluid at the end of the heating or cooling half-cycle period are saved and set as the initial condition for the next half-period. The time required to switch is negligible small.

$\mathrm{T}_{\mathrm{R}, \mathrm{h}}\left(\mathrm{x}, \mathrm{y}, \mathrm{z}, \tau_{\mathrm{h}}\right)=\mathrm{T}_{\mathrm{R}, \mathrm{c}}\left(\mathrm{x}, \mathrm{y}, \mathrm{z}, \tau_{\mathrm{h}, 0}=0\right)$ and $\mathrm{T}_{\mathrm{R}, \mathrm{h}}\left(\mathrm{x}, \mathrm{y}, \mathrm{z}, \tau_{\mathrm{h}, 0}=0\right)=\mathrm{T}_{\mathrm{R}, \mathrm{c}}\left(\mathrm{x}, \mathrm{y}, \mathrm{z}, \tau_{\mathrm{c}}\right)$

The boundary conditions have periodic-flow conditions with constant inlet parameters during the hot/cold period.

$$
\begin{array}{cccc}
\mathrm{T}_{\mathrm{h}}\left(0, \mathrm{y}, \mathrm{z}, \tau_{\mathrm{h}, \tau}\right)=\mathrm{T}_{\mathrm{h}, \mathrm{i}} & \mathrm{Y}_{\mathrm{wv}, \mathrm{h}}\left(0, \mathrm{y}, \mathrm{z}, \tau_{\mathrm{h}, \tau}\right)=\mathrm{Y}_{\mathrm{wv}, \mathrm{h}, \mathrm{i}} & \mathrm{u}_{\mathrm{i}, \mathrm{h}}\left(0, \mathrm{y}, \mathrm{z}, \tau_{\mathrm{h}, \tau}\right)=\mathrm{u}_{\mathrm{m}, \mathrm{i}} & 0 \leq \tau \leq \tau_{\mathrm{h}} \\
\mathrm{T}_{\mathrm{c}}\left(\mathrm{L}, \mathrm{y}, \mathrm{z}, \tau_{\mathrm{c}, \tau}\right)=\mathrm{T}_{\mathrm{c}, \mathrm{i}} & \mathrm{Y}_{\mathrm{wv}, \mathrm{c}}\left(\mathrm{L}, \mathrm{y}, \mathrm{z}, \tau_{\mathrm{c}, \tau}\right)=\mathrm{Y}_{\mathrm{wv}, \mathrm{c}, \mathrm{i}} & \mathrm{u}_{\mathrm{i}, \mathrm{c}}\left(\mathrm{L}, \mathrm{y}, \mathrm{z}, \tau_{\mathrm{c}, \tau}\right)=\mathrm{u}_{\mathrm{m}, \mathrm{i}} & 0 \leq \tau \leq \tau_{\mathrm{h}}
\end{array}
$$
where: $u$ is the velocity of the flow $x=0$ and $x=L, m / s$; indexes " $i$ " and "o"-inlet and outlet; indexes " $m$ " is the average value for the flow and " $\tau$ " is the current moment of the period; indexes " $\mathrm{h}$ " and "c" are the hot and cold flow and ,wv" is water vapor of mass fraction;

During the half-periods, which are equal, $\tau_{\mathrm{h}}=\tau_{\mathrm{c}}$, constant temperature, mass fractions and flow rates of the inlet hot and cold flow are kept. The process of periodic heating and cooling of the matrix continues until the moment of reaching a quasi-steady-state solution, in which fields with equal temperature for each half-periods are established.

\subsection{Thermal properties of fluids and different honeycomb matrix}

The average thermophysical properties of the fluids at operating pressure $p=94659, \mathrm{~Pa}$ for the temperature range $273 \leq \mathrm{T}, \mathrm{K} \leq 293$, [13-17] are shown in Table 2 . The average values of the humid air are determined for the inlet humidity range $2.14 \mathrm{e}-3 \leq \mathrm{d}, \mathrm{kg} / \mathrm{kg} \leq 1.17 \mathrm{e}-2$. Thermal properties of different materials and polymers,[18-23] are shown below in Table 3 .

Table 2. Thermal properties of the fluids for $273 \leq \mathrm{T}, \mathrm{K} \leq 293$ at $\mathrm{p}=94659, \mathrm{~Pa}$.

\begin{tabular}{|c|c|c|c|}
\hline Material name / Unit & $\rho, \mathrm{kg} / \mathrm{m}^{3}$ & $\mathrm{c}_{\mathrm{p}}, \mathrm{J} / \mathrm{kgK}$ & $\lambda, \mathrm{W} / \mathrm{mK}$ \\
\hline Aluminum, $\mathrm{Al}$ - Pure & 2707 & 896 & 220 \\
\hline Copper, $\mathrm{Cu}$ - Pure & 8954 & 380 & 386 \\
\hline Lead - (Plumbum), Pb-Pure & 11373 & 130 & 35 \\
\hline Steel, Chrome-Nickel, $18 \% \mathrm{Cr}-8 \% \mathrm{Ni}$ & 7817 & 460 & 16.3 \\
\hline Ceramics - Ni Cr B Si & 2107 & 495 & 5.7 \\
\hline Alumina Porcelan $-55 \% \mathrm{Al}_{2} \mathrm{O}_{3}-25 \% \mathrm{SiO}_{2}-1 \% \mathrm{MgO}$ & 2050 & 920 & 1.5 \\
\hline Cordierite $-28 \% \mathrm{Al}_{2} \mathrm{O}_{2}-45 \% \mathrm{SiO}_{2}-11 \% \mathrm{MgO}$ & 1500 & 900 & 1.2 \\
\hline Corundum Mullite $-70 \% \mathrm{Al}_{2} \mathrm{O}_{3}-15 \% \mathrm{SiO}_{2}-1 \% \mathrm{MgO}$ & 2300 & 1100 & 1.6 \\
\hline Zirconia Corundum - $60 \% \mathrm{Al}_{2} \mathrm{O}_{3}-20 \% \mathrm{SiO}_{2}-1 \% \mathrm{MgO}$ & 2500 & 1000 & 1.0 \\
\hline PS - Polystyrene & 1050 & 1300 & 0.14 \\
\hline PE-LD - Polyethylene low density & 915 & 1900 & 0.30 \\
\hline PP - Polypropylene & 900 & 1800 & 0.17 \\
\hline PVC-U - Polyvinyl chloride (without plasticizer) & 1380 & 840 & 0.13 \\
\hline PBT - Polybutylene terephthalate & 1300 & 1300 & 0.25 \\
\hline PC - Polycarbonate & 1200 & 1170 & 0.19 \\
\hline PSU - Polysulfone & 1240 & 1370 & 0.15 \\
\hline PTFE - Polytetrafluoroethylene & 2130 & 1000 & 0.23 \\
\hline PVDF - Polyvinylidene fluoride & 1760 & 1400 & 0.19 \\
\hline
\end{tabular}

\begin{tabular}{|c|c|c|c|c|}
\hline Fluid / Unit & $\rho, \mathrm{kg} / \mathrm{m}^{3}$ & $\mathrm{c}_{\mathrm{p}}, \mathrm{J} / \mathrm{kgK}$ & $\lambda, \mathrm{W} / \mathrm{mK}$ & $\mu$, Pa.s \\
\hline Humid Air & $\rho=\mathrm{p} / \mathrm{RT}$ & $\mathrm{c}_{\mathrm{p}}=1010$ & $\lambda=0.02517$ & $\mu=1.676 \mathrm{e}-5$ \\
\hline Water Vapor & $\rho=\mathrm{p} / \mathrm{RT}$ & $\mathrm{c}_{\mathrm{p}}=1896$ & $\lambda=0.01721$ & $\mu=9.461 \mathrm{e}-6$ \\
\hline Water Liquid & $\rho=999$ & $\mathrm{c}_{\mathrm{p}}=4196$ & $\lambda=0.5803$ & $\mu=1.306 \mathrm{e}-3$ \\
\hline
\end{tabular}

Table 3.Thermal properties of the different metals, ceramics and polymers. 


\section{NUMERICAL RESULTS}

\subsection{The values of the fluid flow parameters and the matrix}

The equal initial temperature of the matrix and fluid into the channel is $T_{0}=T_{R}=T=273 \mathrm{~K}$. Constant inlet velocity in the cross-section of the channel during the heating and cooling period is $u_{\mathrm{m}, \mathrm{i}}=0.7 \mathrm{~m} / \mathrm{s}$. With this velocity of the airflow of the inlet channel, the flow rate of the hot and cold flow throughout the regenerator was calculated to be $17 \mathrm{~m}^{3} / \mathrm{h}$. The flow is laminar and the Reynolds number average of the two half-periods is around $\mathrm{Re}=117$. The outlet gauge pressure during the heating and cooling period is $\mathrm{p}=0 \mathrm{~Pa}$. Constant inlet temperatures during the heating and cooling period $T_{h, i}=293 \mathrm{~K}$ and $T_{c, i}=273 \mathrm{~K}$, also constant inlet mass fractions of water vapor during the heating and cooling period are $\mathrm{Y}_{\mathrm{h}, \mathrm{i}}=0.00321, \mathrm{Y}_{\mathrm{c}, \mathrm{i}}=0.00213$. When the condensation process arises on the channel's wall the high inlet humidity is $Y_{\mathrm{h}, \mathrm{i}}=0.0116$. The equal duration of the two half-periods is $\tau_{\mathrm{h}}=\tau_{\mathrm{c}}=90 \mathrm{~s}$.

\subsection{Evaluation of the thermal store materials}

The change of the airflow temperature over time in the outlet's channel operating with humid air is shown in Fig.2. These temperatures were calculated for the average values and were used to evaluate its thermal efficiency by the following expression below, Fig. 3:

$$
\varepsilon=\frac{(\mathrm{W} \times \tau)_{\mathrm{h}} \times\left(\mathrm{T}_{\mathrm{h}, \mathrm{i}}-\overline{\mathrm{T}}_{\mathrm{h}, \mathrm{o}}\right)}{(\mathrm{W} \times \tau)_{\min } \times\left(\mathrm{T}_{\mathrm{h}, \mathrm{i}}-\mathrm{T}_{\mathrm{c}, \mathrm{i}}\right)}=\frac{(\mathrm{W} \times \tau)_{\mathrm{c}} \times\left(\overline{\mathrm{T}}_{\mathrm{c}, \mathrm{o}}-\mathrm{T}_{\mathrm{c}, \mathrm{i}}\right)}{(\mathrm{W} \times \tau)_{\min } \times\left(\mathrm{T}_{\mathrm{h}, \mathrm{i}}-\mathrm{T}_{\mathrm{c}, \mathrm{i}}\right)} \quad \frac{1}{\varepsilon_{\mathrm{r}}}=\frac{1}{2}\left(\frac{1}{\varepsilon_{\mathrm{h}}}+\frac{1}{\varepsilon_{\mathrm{c}}}\right)
$$

Where the average values of the hot and cold fluid heat capacity rate are defined approximately: $\mathrm{W}_{\mathrm{h}}=4.555 .10^{-3} \mathrm{~W} / \mathrm{K}$, and $\mathrm{W}_{\mathrm{c}}=4.887 .10^{-3} \mathrm{~W} / \mathrm{K}$.

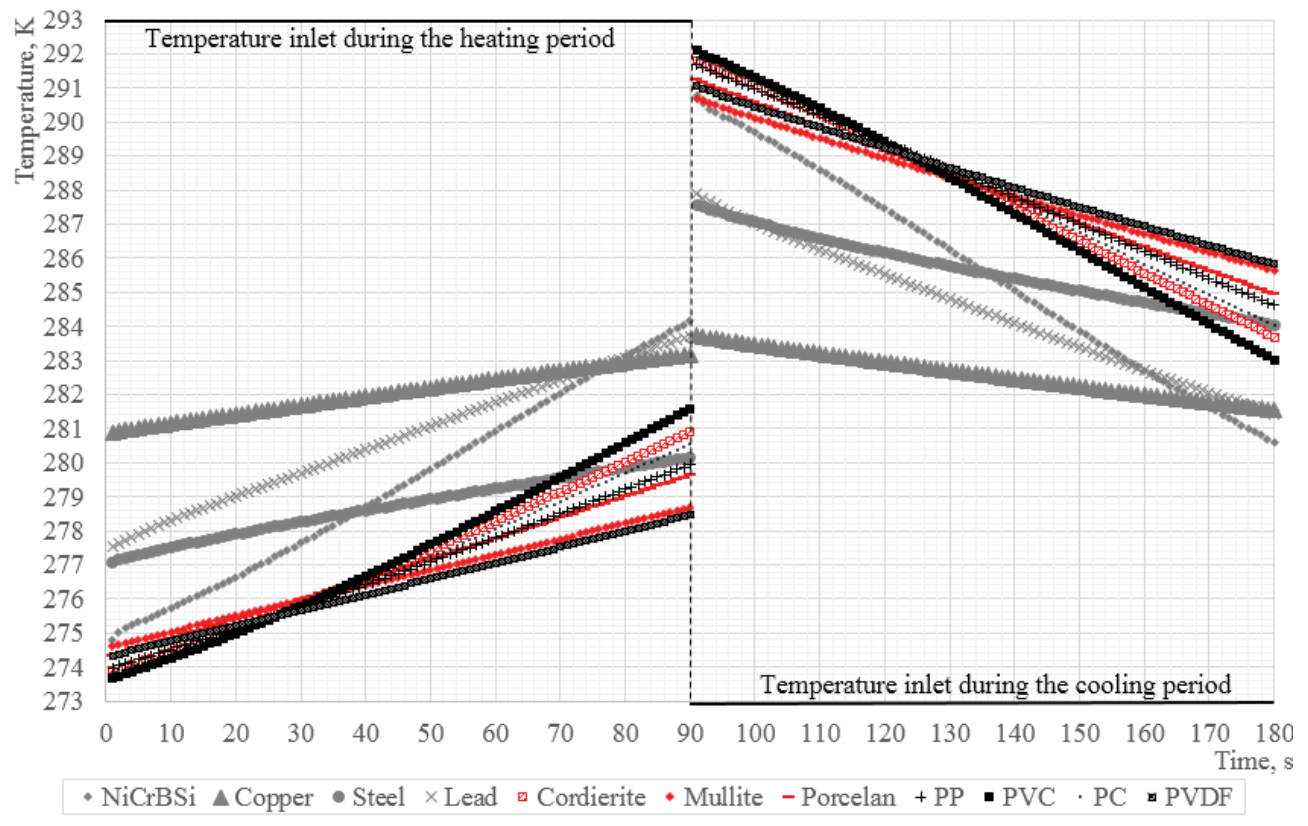

Fig. 2. Average outlet temperature of the quasi-steady-state regime at $\mathrm{x}=0$ and $\mathrm{x}=\mathrm{L}$ for the different honeycomb's materials over the time. 


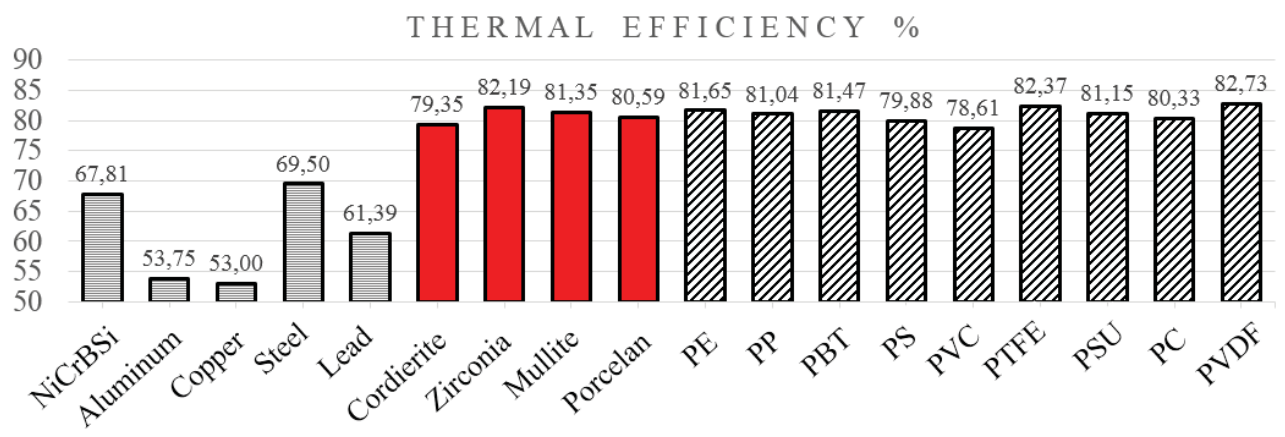

Fig. 3. Bar diagram of the materials' thermal efficiency.

The results of calculations of the influence of indoor air humidity on heat and mass transfer processes in the regenerative heat exchanger are shown in Fig.4. The average temperatures of some types of materials were calculated and were used to evaluate their thermal efficiency by the expression above (6). The average temperatures were used for the last two periods. The comparative results between the materials for different inlet mass fractions, "dry air" $-\mathrm{Y}_{\mathrm{h}, \mathrm{i}}=0.00321$, and "humid air - condensation" $-\mathrm{Y}_{\mathrm{h}, \mathrm{i}}=0.0116$ are shown in Fig.5.

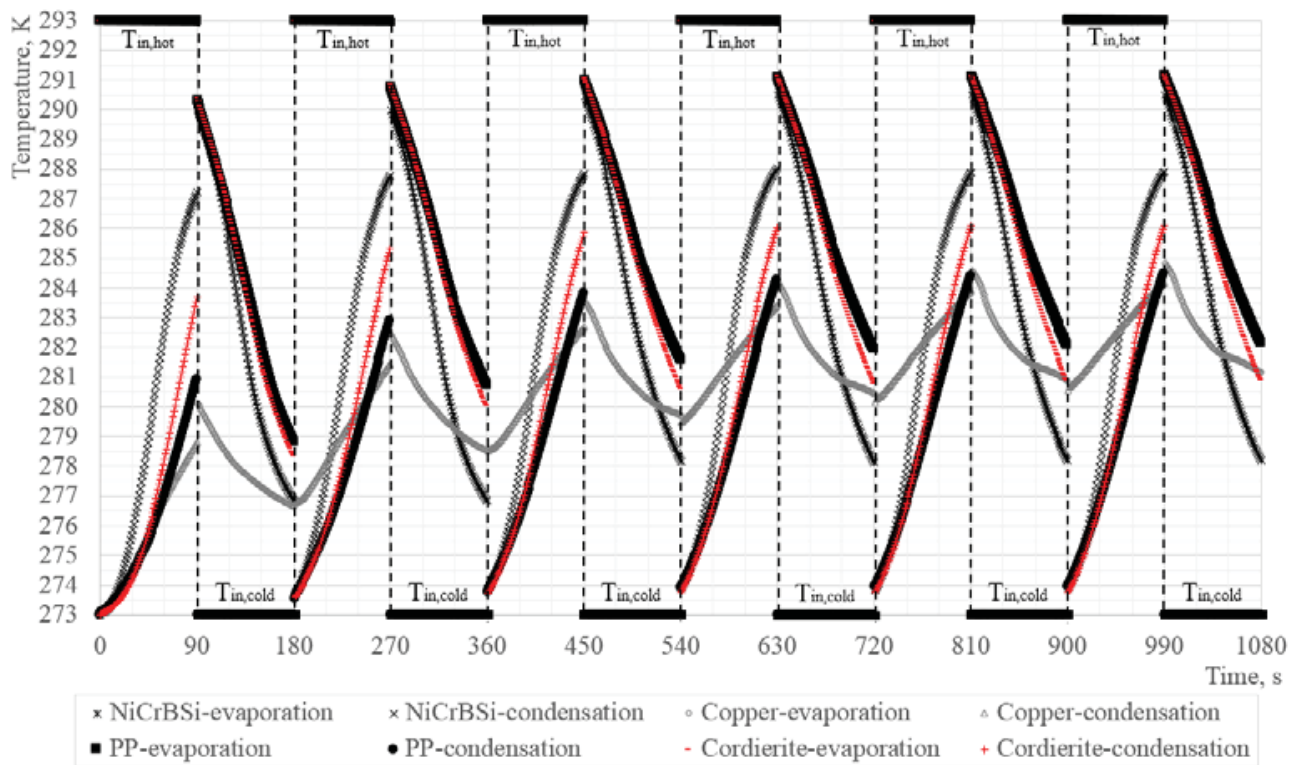

Fig.4. Temperature outlet of the different materials during the condensation-evaporation period.

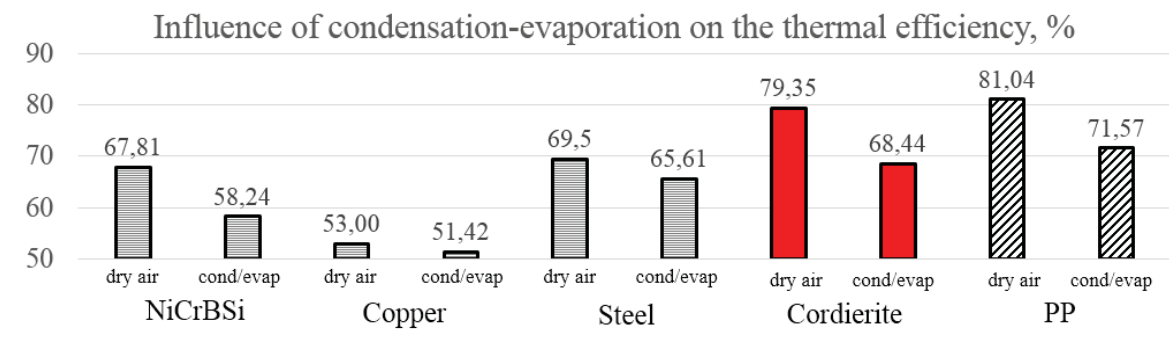

Fig. 5. Influence of the condensation-evaporation on the thermal efficiency in bar diagram 
The influence of the condensation-evaporation process on thermal efficiency gives quite different values for different types of materials and shows a complicated nature, [24].

The results of the research show high thermal efficiency of regenerators with polymer matrix, which makes them suitable for operating conditions in ventilation systems. The use of polymers does not solve the problem of decreasing the thermal efficiency of the regenerator as a result of condensation of moisture, [25] but allows for often replacement or cleaning the matrix in aim to avoid the consequences of its contamination by exhaust air. In addition, polymers, unlike ceramics, do not allow the moisture to penetrate or absorb into the matrix's material and to change its thermal-physical properties and to influence negatively on the thermal efficiency of the regenerator.

\section{Conclusion}

The regenerator model has not an analytical solution when it includes the processes of condensation and evaporation of water vapor of humid air and this requires specific caseby-case studies, $[26,27]$. The developed simulation model of an air regenerator with a phase change reflects the influence of essential parameters on the heat and mass transfer processes in the matrix and allows estimation of local and average values of a large set of physical quantities related to the regenerator operation. Following additional verification and validation procedures, the model could be used to perform numerical experiments to optimize the regenerator. The results could be used to obtain appropriate equations suitable for engineering-applied methods and computer programs in order to evaluate the operation of the regenerator for periods of time under operating conditions close to the real operating conditions. The present results of the numerical simulation in a quasi-steady-state regime operating with humid air give an evaluation of the thermal efficiency of the regenerator for a wide range of different thermal store materials. The comparison of the results shows the advantages of polymers as a thermal store material and the possibility of applying them in fixed regenerators in the field of ventilation systems.

This article is subject of the study of the author's $\mathrm{PhD}$ dissertation.

\section{References}

1. R. A. Ackermann, Cryogenic regenerative heat exchangers. Springer Science \& Business, (2013).

2. K. Thulukkanam, Heat exchanger design handbook. CRC press, (2013).

3. R. K. Shah, D. P. Sekulic, Fundamentals of heat exchanger design. John Wiley \& Sons, (2003).

4. H. J. Bart, S. Scholl, Innovative heat exchangers. Springer, (2017).

5. J. G. Cevallos, Thermal and manufacturing design of polymer composite heat exchangers. PhD diss., (2014).

6. J. D. Anderson, Computational fluid dynamics. The basic with application. New York, McGraw-Hill, Inc., (1995).

7. Ansys Inc., Ansys Fluent theory guide, (2013).

8. ANSYS Inc. ANSYS FLUENT 12.0, User's guide. PathScale, April, (2009).

9. A. Penev, L. Tsokov, N. Penkova, Numerical research of the heat exchange in fixed regenerator for dry air. Technical University of Sofia. Sozopol, September 19, (2019). 
10. A. Penev, L. Tsokov, Analytical and numerical solutions for effectiveness of fixed regenerator for heat recovery with dry air. Varna, September 5, (2019).

11. A. Penev, L. Tsokov, N. Penkova, A conjugate heat transfer in a fixed-bed ceramic regenerator for air conditioning applications. Journal of Chemical Technology and Metallurgy, (2020).

12. D. Sun, J. Xu, Q. Chen, Modeling of the evaporation and condensation phase-change problems with Fluent. Numerical Heat Transfer, Part B: Fundamentals, 66(4):326-342, (2014).

13. N. Nachev, Thermophysical properties of humid air. S.ITUS, (2012).

14. N. Nachev, V. Sharankov, Thermophysical properties of water and steam. S.ITUS, (2011).

15. T. Petrova, The International Association for the Properties of Water and Steam. Revised Release on Surface Tension of Ordinary Water Substance. Moscow, Russia, June, (2014).

16. P. T. Tsilingiris, Thermophysical and transport properties of humid air at temperature range between 0 and $100 C$. Energy Conversion and Management, (2008).

17. W. C. Reynolds, Thermodynamic properties in SI-graphs, tables and computational equations for 40 substances. University, Departement of mechanical engineering, (1979).

18. C. T. Joen, Y. Park, Q. Wang, A. Sommers, X. Han, A. Jacobi, A review on polymer heat exchangers for $H V A C \& R$ applications. International journal of refrigeration, (2009).

19. D. Johnson, Ceramic technology for advanced heat engines. Department of energy, USA, September, (1990)

20. X. Chen, Y. Su, D. Reay, Recent research developments in polymer heat exchangers-A review. Renewable and Sustainable Energy Reviews 60:1367-1386, (2016).

21. M. Pomianowski, P. Heiselberg, Regenerator heat exchanger-calculation of heat recovery efficiency and pressure loss. Different configuration sensitivity analysis. (2017).

22. A. Shchegolkov, A. Shchegolkov, T. Dyachkova, Nanomodified polymer materials for regenerative heat exchangers. AIP Conference Proceedings. Vol. 1899. No. 1. AIP Publishing LLC, (2017).

23. D. M. Zarkadas, K. K. Sirkar, Polymeric hollow fiber heat exchangers: An alternative for lower temperature applications. Industrial \& engineering chemistry research 43(25):8093-8106, (2004).

24. M. Nizovtsev, V. Borodulin, V. Letushko, Infuence of condensation on the effciency of regenerative heat exchanger for ventilation. Applied Thermal Engineering, (2017).

25. Y. A. Aristov, I. V. Mezentsev, V. A. Mukhin, A new approach to heat and moisture regeneration in the ventilation system of rooms. ii. prototype of the real device. Journal of engineering physics and thermophysics, 79(3):577-584, (2006).

26. H. Brouwers, C. Van Der Geld, Heat transfer, condensation and fog formation in crossfow plastic heat exchangers. International journal of heat and mass transfer, 39(2):391-405, (1996).

27. A. Ahsan, Evaporation, condensation and heat transfer. Sep 12, (2011). 